\title{
Agricultural Vegetation Phenology Monitoring by Modis Data Time Series Analysis
}

\author{
Irina Yu. Botvich and Anatoly P. Shevyrnogov* \\ Institute of Biophysics SB RAS \\ FRC "Krasnoyarsk Science Center SB RAS" \\ 50/50 Akademgorodok, Krasnoyarsk, 660036, Russia
}

Received 02.07.2018, received in revised form 06.07.2018, accepted 13.07.2018

To date, many methods have been developed for assessing the state and phenological development of crops using time series of satellite data. Most of them are effective when used ground field measurements. The article presents a new method for determining of the beginning and the end dates of the crops vegetation period. This method is based on a complex analysis of reflective Normalized Difference Vegetation Index (NDVI) and radiative - Land Surface Temperature (LST) characteristics of vegetation. The features of agrophytocenoses phase portraits in the twodimensional space LST and NDVI are studied. An analysis of the phenological variability of agrophytocenoses during the vegetation periods of 2006, 2016-2017 in the south of the Krasnoyarsk Territory and the Republic of Khakassia has been performed. The distinctive features of phase portraits in space (LST, NDVI) of agrophytocenosis from other vegetation species are revealed. The possibility of determining the time and duration of the phenological states of agrophytocenosis, the features of the transition from one state to another, is shown.

Keywords: crop phenology, growing season, remote sensing, Modis data, NDVI, LST.

Citation: Botvich I.Yu., Shevyrnogov A.P. Agricultural vegetation phenology monitoring by modis data time series analysis, J. Sib. Fed. Univ. Eng. technol., 2018, 11(6), 624-634. DOI: 10.17516/1999-494X-0080.

C) Siberian Federal University. All rights reserved

This work is licensed under a Creative Commons Attribution-NonCommercial 4.0 International License (CC BY-NC 4.0).

* Corresponding author E-mail address: irina.pugacheva@mail.ru 


\section{Мониторинг фенологического развития сельскохозяйственной растительности \\ на основе анализа временных рядов \\ спутниковых данных Modis}

И.Ю. Ботвич, А.П. Шевырногов Институт биофизики СО РАН ФИЦ «Красноярский научный чзентр СО РАН» Россия, 660036, Красноярск, Академгородок, 50/50

К настоящему времени разработано множество методов оценки состояния и фенологического развития посевов по временным рядам спутниковых данных. Большинство из них эффективны только при использовании наземных полевых измерений. В статье представлен новый метод определения времени начала и конща вегетационного периода посевов сельскохозяйственных культур. Данныйметодоснованнакомплексном анализеотражательных-NormalizedDifference Vegetation Index (NDVI) и излучательных - Land Surface Temperature (LST) характеристик растительности. Изучены особенности фазовых портретов агрофитоценозов, построенных в двумерном пространстве значений LST и NDVI. Выполнен анализ фенологической изменчивости агрофиточенозов в периоды вегетации 2006, 2016-2017 г2. на юге Красноярского края и Республики Хакасия. Выявлены отличия фазовых портретов агрофиточенозов от других видов растительности в пространстве (LST, NDVI). Показана возможность определения времени и длительности фенологических состояний агрофитоиенозов, особенностей перехода из одного состояния в другое.

Ключевыеслова: фенология, сельскохозяйственные культуры, периодвегетации, дистанциионое зондирование, Modis, NDVI, LST.

\section{Введение}

Площадь сельскохозяйственных угодий составляет $12 \%$ от всей площади суши на поверхности Земли. Изменение фенологического развития сельскохозяйственных растений может оказать важное влияние на поверхностные углеродные и водные потоки, гидрологические процессы, региональный климат и глобальный углеродный цикл [1]. Проведенные в последнее десятилетие исследования доказали, что изменение климата (повышение температуры, изменение режимов осадков и изменение сезонных циклов) оказывает влияние на сельское хозяйство [2]. Подробное изучение фенологического развития растительности в региональном и глобальном масштабах улучшает наше понимание межгодовых изменений растительности в наземных экосистемах, климатических и иных изменений окружающей среды $[3,4]$.

Получение достоверной и оперативной информации о фенологическом состоянии растений посевов не всегда возможно или проблематично. Фенологические наблюдения на местах очень трудоемкие и дорогостоящие, и не могут быть легко обобщены и систематизированы [5]. Использование данных дистанционного зондирования позволяет решить данную проблему. Посредством использования спектральных индексов растительности определяются объем фитомассы, проективное покрытие, начало и конец периода вегетации [6, 7]. Получая информацию о сроках фенологических событий, особенно начале, конце периода вегетации и в течение 
фотосинтетического активного периода роста, появляется возможность оценивать сезонные и межгодовые изменения экосистемы и улучшить понимание динамических взаимодействий между атмосферой и биосферой [8]. Разработка методов дистанционного определения начала и конца вегетации, смены фаз развития культур открывает новые возможности в развитии методов точного земледелия. Использование данных дистанционного зондирования позволяет оценивать состояние культур на отдельных участках в пределах одного поля, определять их неоднородность, оперативно оценивать состояние посевов на территориально удаленных участках. Данные о стадиях фенологического развития растительности посевов являются ключевой информацией, необходимой при оценке их состояния и прогнозирования урожайности.

Использование спутниковой информации предоставляет возможность дистанционно определять время наступления и окончания периода вегетации как в региональном, так и в глобальном масштабах. Выполнение этой задачи возможно при использовании ежедневной спутниковой информации NOAA-AVHRR, SPOT-Vegetation или Terra/Aqua-MODIS. Первые данные о продолжительности периода вегетации были получены в результате обработки спутниковой информации NOAA-AVHRR [9]. Более точные данные были получены с появлением прибоpa Moderate Resolution Imaging Spectroradiometer (MODIS) на борту спутников Terra и Aqua [6]. Высокое временное разрешение данных спектрорадиометра MODIS позволяет эффективно контролировать сезонную изменчивость сельскохозяйственных культур. Быстрое получение таких данных в глобальном масштабе также является необходимым предварительным условием для точного измерения площади посевных площадей в крупных регионах и позволяет проводить их оценку и картографирование [10].

В настоящее время используется ряд методов для определения границ периода вегетации растительности: математические (логистические) методы [6, 11-14] и пороговые [15- 20]. Они имеют ряд недостатков, которые ограничивают их применение. Так, величина порога в «пороговом методе» определяется опытным путем с привлечением полевых геоботанических данных. Параметры логистических уравнений определяются статистическим способом, но точность логистического метода снижается за счет большого числа статистически определяемых параметров (более двух) [20].

Настоящая статья посвящена изложению результатов изучения изменчивости фазовых портретов сельскохозяйственной растительности, построенных в двумерном пространстве значений радиационной температуры (LST) и Normalized Difference Vegetation Index (NDVI). Новые возможности дистанционного мониторинга фенологической изменчивости растительности осуществляются на основе комплексного анализа отражательных (NDVI) и излучательных (LST) характеристик растительных объектов. Разработана методика автоматического определения границ вегетационного периода растительности без привлечения полевых геоботанических данных.

\section{2. Материалы и методы}

Объектом исследований являются посевы сельскохозяйственных (c/x) культур: пшеница (Triticum acstivum), овес (Avena), гречиха (Fagópyrum), ячмень (Hordéum vulgáre). Изучаемые посевы этих культур расположены на территории Емельяновского (№ 1) и Минусинского (№ 2) районов Красноярского края, Алтайского района (№ 3) Республики Хакасия (рис. 1).

$$
-626-
$$




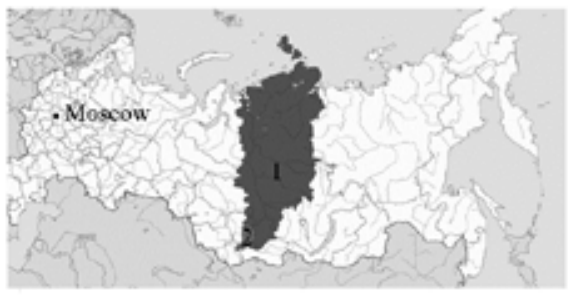

Russia

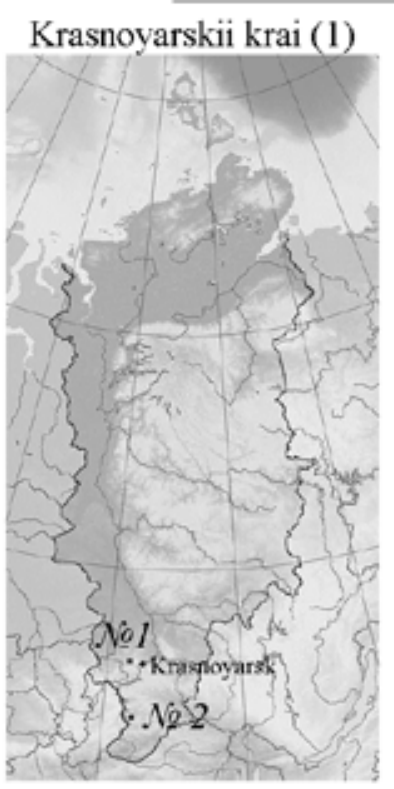

Republic of Khakassia (2)

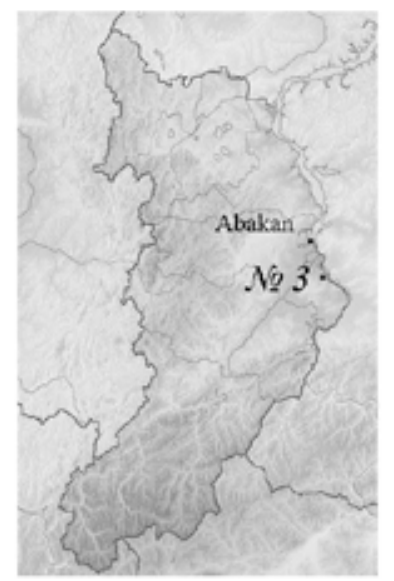

Рис. 1. Карта-схема расположения исследуемых посевов сельскохозяйственных культур. Тестовый участок № 1 расположен в Емельяновском районе Красноярского края (посевы пшеницы, ячменя); № 2 в Минусинском районе Красноярского края (посевы пшеницы, гречихи); № 3 - в Алтайском районе Республики Хакасия (посевы овса)

Fig. 1. Location of the investigated agricultural crops on the map-scheme. Test area № 1 is located in the Emelyanovsk district of the Krasnoyarsk Territory (wheat and barley crops); № 2 - in the Minusinsk District of the Krasnoyarsk Territory (wheat and buckwheat crops); № 3 - in the Altai region of the Republic of Khakassia (oats crops)

Исследование основывается на 8-дневных данных спектрорадиометра MODIS Terra (EOS $\mathrm{AM}$ ) и Aqua (EOS PM) с пространственным разрешением 250-м и 1000-м-продукты MOD09Q1, MOD11A2, MYD09Q1 and MYD11A2 (Collection 6, tile: h23v03). Продукты MODIS распространяются через NASA's Earth Observing System Data and Information System (EOSDIS). Пространственное разрешение данных MODIS 250-м (MOD09Q1, MYD09Q1) и 1000-м (MOD11A2, MYD11A2) составляют 231.7 м и 930 м соответственно.

В продуктах MOD09GQ, MYD09GQ содержатся спутниковые данные о спектральном отражении поверхности, измеренные в красном (620-670 нм), ближнем инфракрасном (841876 нм) диапазонах (http://modis.gsfc.nasa.gov/). Расчет NDVI базируется на данных красного $(R E D)$ и ближнего инфракрасного (NIR) диапазонов оптического спектра [21]:

$$
N D V I=\frac{N I R-R E D}{N I R+R E D} .
$$


Радиационная температура, восстановленная по спутниковым данным, дает информацию о температуре поверхности исследуемого объекта (верхней границы растительного покрова, почвы). Исследование основывается на данных продуктах MOD11A2, MYD11A2. В данных продуктах предоставляются 8-дневные данные спутников Terra и Aqua, соответственно, о температуре поверхности Земли с пространственным разрешением 1000 м (http://modis.gsfc.nasa. gov/). Данные имеют 3-й уровень обработки. Значения температуры поверхности восстанавливаются по измерениям радиометром Modis в тепловых инфракрасных каналах № 31 (10.78011.280 мкм) и № 32 (11.770-12.270 мкм).

\section{3. Результаты и обсуждения}

Проведение комплексного анализа отражательных и излучательных характеристик растительных объектов открывает новые возможности дистанционного мониторинга фенологической изменчивости растительности. Использование NDVI позволяет оценивать физиологическое состояние, динамику фитопигментов и биологическую продуктивность растений. Радиационная температура (LST), восстановленная по спутниковым данным, дает информацию о температуре поверхности исследуемого объекта (верхней границы растительного покрова, почвы).

Одним из эффективных методов анализа динамической системы является получение и изучение ее «фазового портрета». Он дает возможность установить равновесные (стационарные) состояния системы и характер ее динамики при отклонении от них, позволяет сделать выводы о характере изменений изучаемых переменных. Построение фазовых портретов растительных объектов производилось следующим образом: по оси абсцисс откладывались значения LST, по оси ординат - значения NDVI. Интервал дискретности равен 8 дням. Каждая точка на плоскости соответствует определенному состоянию объекта. Суть метода динамического фазового портрета состоит в рассмотрении траектории системы в координатах LST, NDVI.

В течение сезонного развития растительное сообщество неоднократно претерпевает изменения состояния - фазовые переходы (всходы, кущение, созревание и т.д.) (рис. 2). Рассмотрим изменение фазовых траекторий агрофитоценозов в пространстве (LST, NDVI).

Анализ полученных данных показал, что форму фазовой кривой у=NDVI(LST) растительного объекта условно можно разделить на несколько зон:

1. Форма участка фазовой кривой в виде плато в начале вегетационного периода свидетельствует об отсутствии вегетации (участок № 1 на кривой рис. 3). В отличие от естественной растительности, посев семян сельхозкультур производится в физически спелую почву. Естественная растительность не столь требовательна к состоянию почвы. Процесс ее выхода из состояния зимнего покоя начинается при первом оттаивании корнеобитаемого слоя почв. Наличие открытой почвы (без растительного покрова) продолжительный период времени отражается на форме фазового портрета растительности посевов сельхозкультур в виде характерного плато (рис. 4). Ход кривой нарушается только тогда, когда растения накапливают требуемый для их роста объем тепловой энергии (Р1). Критическая точка в функционировании фитоценоза P1 свидетельствует о начале вегетации растительности. 


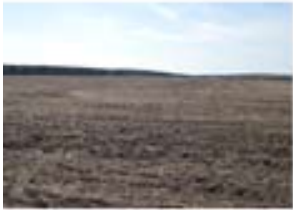

24 april

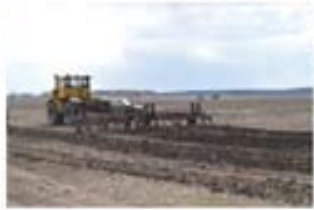

19 may

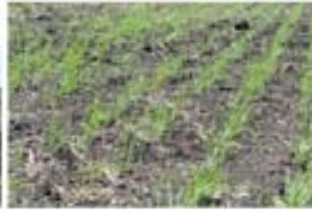

5 june

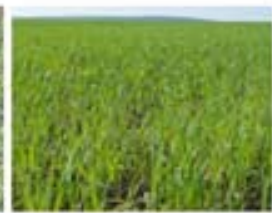

21 july

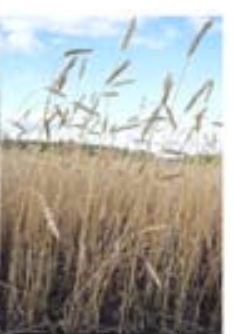

21 august

Рис. 2. Фотографии посева пшеницы (тестовый участок расположен в Емельяновском районе) в течение периода весна - лето 2016 г.

Fig. 2. Pictures of wheat crop (the test area is located in the Emelyanovsk district) during the period springsummer 2016

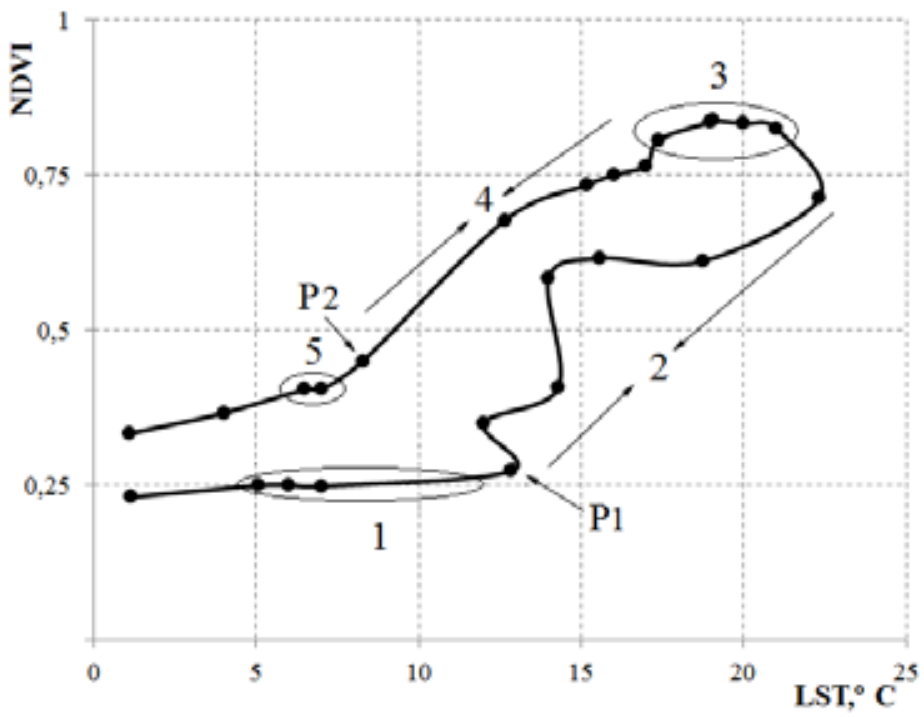

Рис. 3. Иллюстрация фазового портрета растительного объекта в пространстве (LST, NDVI). Цифры у кривой указывают фенологическую фазу: 1 - отсутствие вегетации, предвегетационный период; 2 - рост биомассы наземных органов (первый этап вегетационного периода); 3 - сезонный максимум биомассы; 4 - созревание семян, увядание листвы; 5 - послевегетационный период; P1, Р2 - начало и окончание вегетации растительности

Fig. 3. Illustration of the phase portrait of a plant object in space (LST, NDVI). The figures in the curve indicate the phenological phase: 1 - absence of vegetation, pre-vegetation period; 2 - growth of biomass of terrestrial organs (the first stage of the vegetative period); 3 - seasonal maximum of biomass; 4 - maturation of seeds, wilting leaves; 5 - non-vegetation period; P1, P2 - the beginning and the end of the vegetation period

2. Преодолев порог, скорость прироста биомассы наземных органов резко увеличивается. Это отражается на всех кривых фазовых портретов в виде многократного увеличения значений NDVI (участок № 2 на кривой рис. 3). Посевы сельхозкультур находятся на стадиях всходы, кущение.

3. Кривая фазового портрета на участке № 3 (рис. 3) имеет вытянутую вдоль оси абсцисс форму. Следовательно, основной вклад в формирование кривой вносит изменчивость 
значений радиационной температуры (от 10 до $30^{\circ} \mathrm{C}$ ). Значения NDVI изменяются несущественно. Для посевов сельхозкультур увеличение данных значений (на 10-12 \%) обусловлено увеличением общего проективного покрытия в связи с ростом генеративных органов (рис. 4).

4. Участок № 4 кривой фазового портрета (рис. 3) указывает на то, что посевы сельхозкультур находятся в стадии созревания, происходит налив и созревание зерна. Переход от восковой стадии созревания до полной спелости сопровождается уменьшением общего проективного покрытия, сменой аспекта растений (от зеленого до желтого), увеличением количества ветоши и мортмассы. Критическая точка в функционировании фитоценоза Р2 свидетельствует об окончании вегетации растительности.

5. Участок № 5 кривой фазового портрета (рис. 3) отражает процессы после вегетационного периода - посевы сельхозкультур убраны.

Обработка полученных данных показала возможность автоматического определения времени начала и окончания вегетации растительности (без привлечения геоботанических описаний). Для этого необходимо произвести расчет величины угла наклона скользящей прямой $(\alpha)$, проходящей через каждые три точки фазового портрета с единичным шагом. В расчете необходимо рассмотреть все значения в интервале от $\mathrm{NDVI}_{\mathrm{o}}$ до $\mathrm{NDVI}_{0.5}\left(\mathrm{NDVI}_{0}-\right.$ значения NDVI с температурой выше $5{ }^{\circ} \mathrm{C}$ при условии, что во все последующие дни температура выше $0{ }^{\circ} \mathrm{C}$; $\mathrm{NDVI}_{0.5}$ - значения NDVI не более 0.5 ). Началом и концом вегетации считаются даты с максимальными величинами углов наклона скользящих прямых, построенных между фазами № 1-2, № 4-5 соответственно.

Такой подход справедлив для разработки общих принципов оценки динамики вегетационного периода растений. В реальных условиях конкретного года колебания температуры могут искажать идеальную форму фазовой кривой. Это, с одной стороны, усложняет расчеты, а с другой - позволяет увидеть характер биоклиматического воздействия на растения в условиях климатических изменений конкретного года наблюдений (рис. 4).

В связи с большим объемом спутниковой информации проведена автоматизация процессов предварительной и тематической обработки путем разработки программного обеспечения на языке IDL 6.0 (the Interactive Data Language). Алгоритм обработки данных включает следующую последовательность действий:

1. Преобразование проекции снимков из Sinusoidal projection в Universal Transverse Mercator (UTM) с помощью программы MODIS Reprojection Tool.

2. Построение маски выпавших значений.

3. Расчет средних значений NDVI (Terra, Aqua) за 8-дневный период.

4. Расчет средних значений LST (Terra, Aqua) за 8-дневный период с пространственным разрешением 250 м.

5. Восстановление пропущенных данных, их нормирование.

6. Расчет времени перехода среднесуточной температуры через порог $5{ }^{\circ} \mathrm{C}$ в период подъема температуры.

7. Расчет времени начала и окончания периода вегетации растительности посевов сельскохозяйственных культур по вышеизложенному алгоритму. 


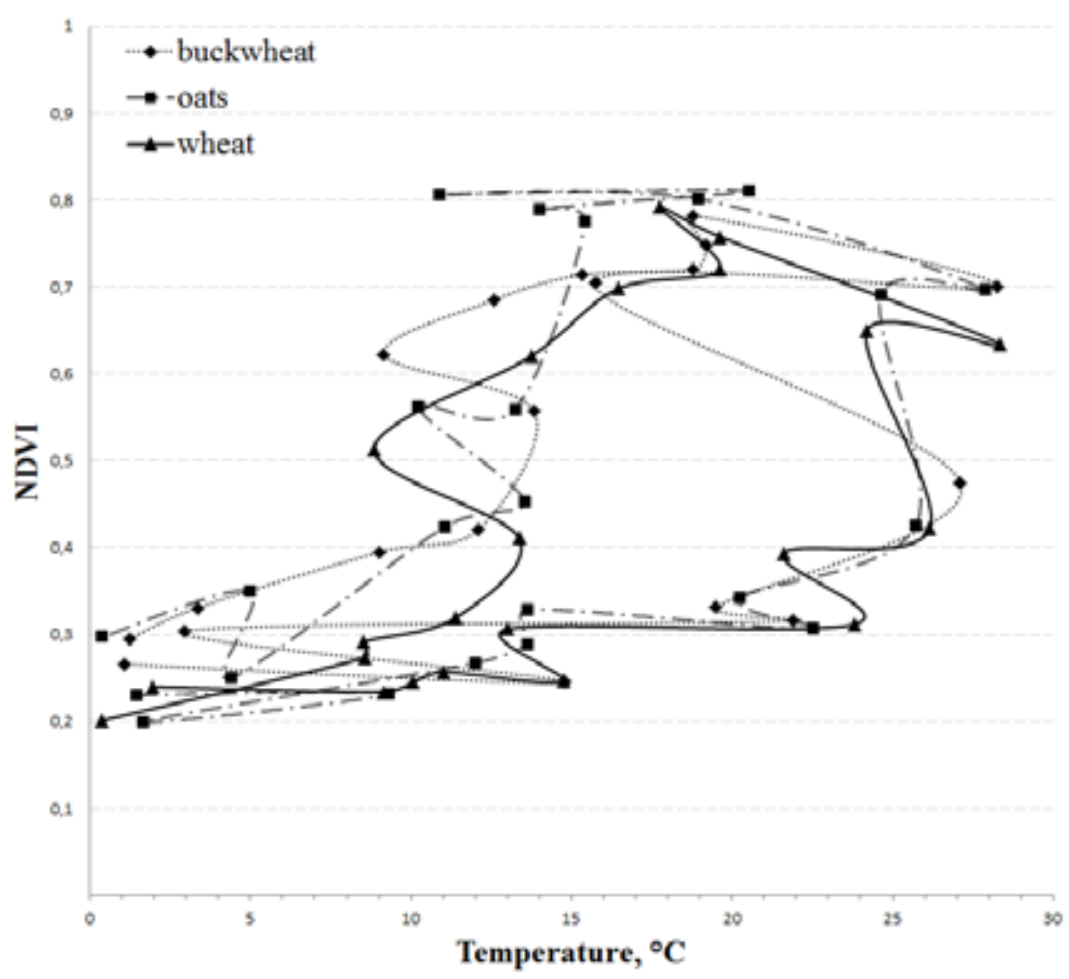

Рис. 4. Фазовые траектории посевов сельскохозяйственных культур в пространстве (LST, NDVI), 2006 г.

Fig. 4. Phase trajectories of agricultural crops in the space (LST, NDVI), 2006

В табл. 1 представлены результаты расчета времени начала и окончания периода вегетации растительности посевов сельскохозяйственных культур на территории Емельяновского района Красноярского края (рис. 5) по спутниковым данным.

В ходе проведенных полевых наземных исследований установлено, что в 2016 г. первые всходы на полях № 2 и 3 появились 26 мая, в 2017 г. - 24 мая. 2017 г. характеризуется более ранним началом вегетации и большим приростом активных температур по сравнению с 2016 г. В 2016 г. переход среднесуточной температуры воздуха через $5{ }^{\circ} \mathrm{C}$ наблюдался с 17 апреля, в 2017 г. на 6 дней раньше - 11 апреля. Сумма активных температур в начале вегетации в течение периода с апреля по май в 2016 г. значительно меньше суммы активных температур в 2017 г. (на 43 \% в апреле, на 30 \% в мае). Урожайность на поле № 1 в 2016 г. составила 28.2 ц/га; на поле № 2 - 15.3 ц/га (2016 г.), 46.1 ц/га (2017 г.); на поле № 3 - 16.6 ц/га (2016 г.), 37.6 ц/га (2017 г.). Уборка культур проводилась 2-3 сентября 2016 г. и 30 августа 2017 г. Таким образом, данные, полученные в результате обработки спутниковой информации, согласуются с данными, полученными в ходе наземных геоботанических обследований исследуемых участков.

\section{Выводы}

В данной работе представлен новый метод определения времени начала и конца периода вегетации растительности посевов сельскохозяйственных культур. Данный метод основан на 


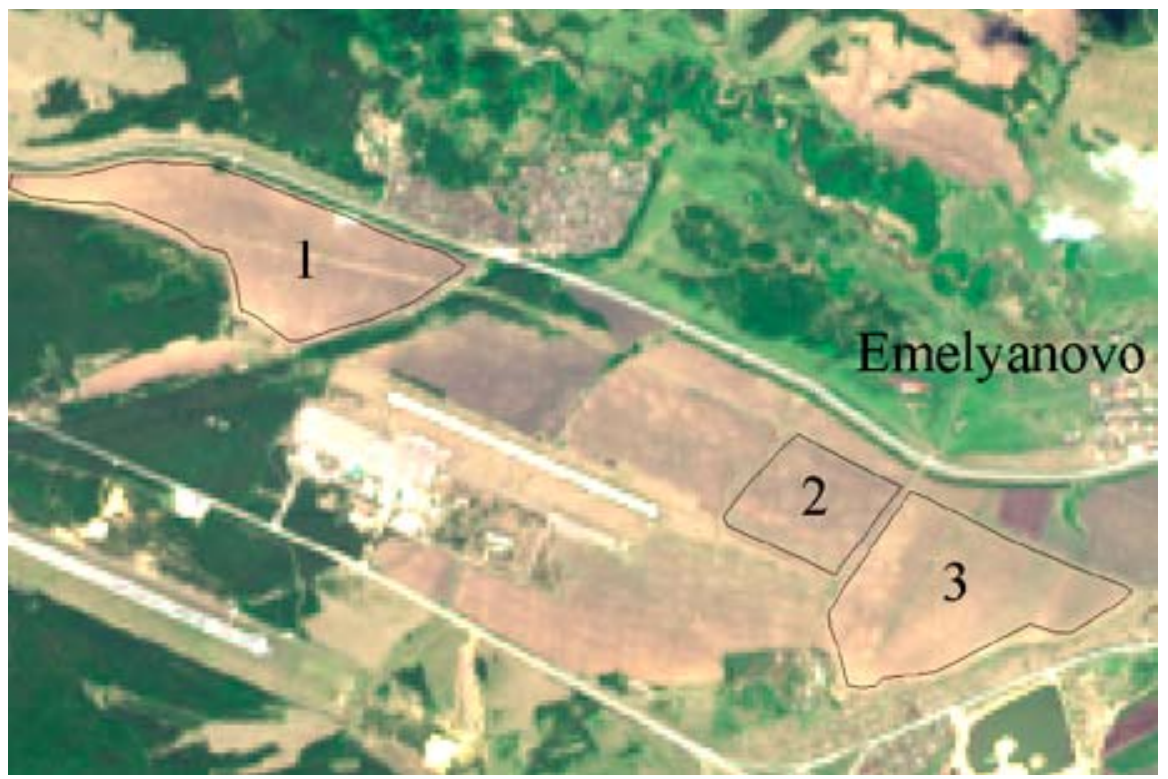

Рис. 5. Тестовый участок № 1, Емельяновский район Красноярского края окрестности п. Емельяново (поле № 1 - ячмень в 2016 г., пар в 2017 г.; поле № 2 - пшеница (2016 г. и 2017 г.); поле № 3 - пшеница (2016 г. и 2017 г.)

Fig. 5. Test area №. 1, Emelyanovskiy district, Krasnoyarsk region, near the village of Emelyanovo (field № 1 barley in 2016, fallow in 2017, field № 2 - wheat (2016 and 2017), field № 3 - wheat (2016 and 2017)

Таблица 1. Время начала и окончания периода вегетации растительности посевов сельскохозяйственных культур Емельяновского район Красноярского края в 2016 и 2017 гг.

Table 1. Time of the beginning and the end of the crops vegetation period, the Yemelyanovskiy district of the Krasnoyarsk Territory in 2016 and 2017

\begin{tabular}{|c|c|c|}
\hline $\begin{array}{c}\text { Номер тестового участка, поля } \\
\text { (год) }\end{array}$ & начало & оремя периода вегетации \\
\hline № 1, поле 1 (2016 г.) & $16.05-23.05$ & $28.08-04.09$ \\
\hline № 1, поле 2 (2016 г.) & $24.05-31.05$ & $28.08-04.09$ \\
\hline № 1, поле 3 (2016 г.) & $24.05-31.05$ & $28.08-04.09$ \\
\hline № 1, поле 2 (2017 г.) & $17.05-24.05$ & $29.08-05.09$ \\
\hline № 1, поле 3 (2017 г.) & $17.05-24.05$ & $29.08-05.09$ \\
\hline
\end{tabular}

комплексном анализе отражательных (Normalized Difference Vegetation Index) и излучательных (радиационной температуры, LST) характеристик растительных объектов.

Проведены комплексные исследования фенологической изменчивости агрофитоценозов на тестовых участках Емельяновского района Красноярского края и Республики Хакасия в 2006, 2016 и 2017 гг. Выполненные фенологические исследования основываются на спутниковых и наземных геоботанических данных. Проведение полевых геоботанических исследований агрофитоценозов позволило разработать и верифицировать методику дистанционного определения границ вегетации растительности по спутниковым данным. 
Выявлены отличительные особенности фазовых портретов агрофитоценозов от других видов растительности в пространстве (LST, NDVI). Установлено, что изучение фазовых портретов растительности позволяет повысить информативность имеющихся данных NDVI и радиационной температуры. Направление движения вектора $\Delta$ NDVI/ALST вдоль фазовой траектории растительных объектов юга Красноярского края - против часовой стрелки. Показана возможность определения границ фенологических состояний агрофитоценозов, области перехода из одного состояния в другое.

\section{Список литературы}

[1] Tao F., Zhang S., Zhang Z. Spatiotemporal changes of wheat phenology in China under the effects of temperature, day length and cultivar thermal characteristics, Europ. J. Agronomy, 2012, 43, 201-212.

[2] Brown M.E, K.M. de Beurs, Marshall M. Global phenological response to climate change in crop areas using satellite remote sensing of vegetation, humidity and temperature over 26 years, Remote Sensing of Environment, 2012, 126, 174-183.

[3] Zeng L., Wardlow Brian D., Wang R., Shan J., Tadesse T., Hayes M., Li D. A hybrid approach for detecting corn and soybean phenology with time-series MODIS data, Remote Sensing of Environment, 2016, 18, 237-250.

[4] Zhang X., Friedl M.A., Schaaf C.B., Strahler A.H., Hodges J.C.F., Gao F., Reed B.C., Huete A. Monitoring vegetation phenology using MODIS, Remote Sensing of Environment, 2003, 84 (3), 471-475.

[5] Satir O., Berberoglu S. Crop yield prediction under soil salinity using satellite derived vegetation indices, Field Crops Research, 2016, 192, 134-143.

[6] Zhang X., Mark A.F., Crystal B.S., Alan H.S., John C.F.H., Gao F., Bradley C.R., Alfredo H. Monitoring vegetation phenology using MODIS, Remote Sensing of Environment, 2003, 84, 471-475.

[7] Hmimina G., Dufrêne E., Pontailler J.-Y., Delpierre N., Aubinet M., Caquet B., A. de Grandcourt, Burban B., Flechard C., Granier A., Gross P., Heinesch B., Longdoz B., Moureaux C., Ourcival J.-M., Rambal S., L. Saint André, Soudani K. Evaluation of the potential of MODIS satellite data to predict vegetation phenology in different biomes: An investigation using ground-based NDVI measurements, Remote Sensing of Environment, 2013, 132, 145-158.

[8] Verma M., Friedl M.A., Finzi A., Phillips N. Multi-criteria evaluation of the suitability of growth functions for modeling remotely sensed phenology, Ecological Modelling, 2016, 323, 123-132

[9] Reed B.C., Brown J.F., VanderZee D., Loveland T.R., Merchant J.W., Ohlen D.O. Measuring phenological variability from satellite imagery, Journal of Vegetation Science, 1994, 5, 703-714.

[10] Pan Y., Li L., Zhang J., Liang S., Zhu X., Sulla-Menashe D. Winter wheat area estimation from MODIS-EVI time series data using the Crop Proportion Phenology Index, Remote Sensing of Environment, 2012, 119, 232-242.

[11] Fisher J. I., Mustard J. F., Vadeboncoeur M. A. Green leafphenology at Landsat resolution:scaling from the field to the satellite, Remote Sensing of Environment, 2006, 100 (2), 265.

[12] Ahl D.E., Gower S.T., Burrows S.N., Shabanov N.V., Myneni R.B., Knyazikhin Y. Monitoring spring canopy phenology of a deciduous broadleaf forest using MODIS, Remote Sensing of Environment, 2006, 104, 88-95. 
[13] Fisher J.I., Mustard J.F., Cross-scalar satellite phenology from ground Landsat and MODIS data, Remote Sensing of Environment, 2007, 109 (3), 261-273.

[14] Cao R., Chen J., Shen M., Tang Y. An improved logistic method for detecting spring vegetation phenology in grasslands from MODIS EVI time-series data, Agricultural and Forest Meteorology, 2015, 200, 9-20.

[15] White M.A., Thornton P.E., Steven W.R. A continental phenology model for monitoring vegetation responses to interannual climatic variability, Global Biogeochemical Cycles, 1997, 11, $217-234$.

[16] White M.A., Nemani R.R. Canopy duration has little influence on annual carbon storage in the deciduous broadleaf forest, Global Change Biology, 2003, 9, 967-972.

[17] White M.A., Nemani R.R. Real-time monitoring and short-term forecasting of land surface phenology, Remote Sensing of Environment, 2006, 104, 43-49.

[18] Kim S., Kang S., Lim J.-H., Chun J.-H., Sung J.-H. Regional parameterization of canopy onset models using MODIS and flowering onset data, Ecological Modelling, 2012, 247, 190.

[19] Suzuki R., Nomaki T., Yasunari T. West-east contrast of phenology and climate in northern Asia revealed using a remotely sensed vegetation index, International Journal of Biometeorology, 2003, 47, 126-138.

[20] Медведева М.А., Барталёв С.А., Лупян Е.А., Матвеев А.М., Толпин В.А., Пойда А.А. Возможности оценки момента наступления вегетационного сезона на основе спутниковых и метеорологических данных, Современные проблемы дистанционного зондирования Земли из космоса, 2008, 5 (2), 313-321. [Medvedeva M.A., Bartalev S.A., Lupyan E.A., Matveev A.M., Tolpin V.A., Poyda A.A. Possibilities for assessing the moment of the onset of the growing season based on satellite and meteorological data, Modern problems of remote sensing of the Earth from space, 2008, 5 (2), 313-321 (in Russian)]

[21] Deering D.W. Rangeland reflectance characteristics measured by aircraft and spacecraft sensors. Ph.D. Dissertation, Texas A \& M University, College Station, TX, 1978, 338. 